\title{
Studi Literatur: Peran Guru Pendidikan Khusus di Sekolah Inklusi
}

\author{
Nissa Amalia*, Farida Kurniawati \\ Program Studi Psikologi Pendidikan, Fakultas Psikologi, Universitas Indonesia \\ *Corresponding Author. Email: nissa.amalia@gmail.com
}

\begin{abstract}
The research was carried out to know the role played by teacher assistants in inclusive schools. The research method used for this study is a systematic review by capturing articles related to the research topic published between 2009-2019 through the electronic search engine Taylor and Francis Online. The initial search found 24 articles and then selected based on exclusive criteria, in which there were ten articles identified using thematic data analysis techniques. The results found that role of a teacher assistant is role pedagogic and non-pedagogic. Pedagogic roles include learning, giving assignments, helping students complete assignments, performing assignments, making IEP (individualized educational program), assessing and managing student behavior while non-pedagogic roles include emotional support, consulting, facilitating teachers, students, and parents. The results also show the importance of teacher assistants having competencies according to their educational background and building collaborative learning between classroom teachers and teacher assistants in the classroom. Limitations and recommendations for future research are discussed in this paper.
\end{abstract}

\begin{abstract}
Abstrak: Penelitian ini bertujuan untuk menganalisis peran yang dilakukan oleh guru pendidikan khusus di sekolah inklusi. Metode penelitian yang digunakan adalah review literatur yang sistematis dengan menjaring artikel-artikel yang terkait dengan tema penelitian yang diterbitkan dengan rentang waktu 20092019 melalui mesin pencarian elektronik Taylor and Francis Online. Pencarian awal didapatkan 24 artikel kemudian dipilih berdasarkan kriteria eksklusif sehingga didapatkan 10 artikel yang dianalisa menggunakan teknik data tematik. Hasil studi menunjukkan bahwa peran guru pendidikan khusus yaitu peran pedagogik dan non pedagogik. Peran pedagogik meliputi pengajaran, memberikan instruksi tugas, membantu siswa fokus menyelesaikan tugas, membuat PPI (program pembelajaran individual), melakukan asesmen dan mengelola perilaku siswa sedangkan peran non pedagogik meliputi dukungan emosional, konsultasi, fasilitator antara guru, siswa, dan orang tua. Hasil penelitian juga menunjukkan pentingnya guru pendidikan khusus memiliki kompetensi sesuai dengan pendidikannya dan membangun pembelajaran kolaboratif antara guru kelas dengan guru pendidikan khusus di kelas. Keterbatasan penelitian dan saran penelitian selanjutnya dibahas di bagian terakhir.
\end{abstract}

Article History

Received: 12-03-2021

Revised: 24-04-2021

Accepted: 03-05-2021

Published: 07-06-2021

\section{Key Words:}

Disability Students, Inclusive School,

Teacher Assistants.

\section{Sejarah Artikel}

Diterima: 12-03-2021

Direvisi: 24-04-2021

Disetujui: 03-05-2021

Diterbitkan: 07-06-2021

\section{Kata Kunci:}

Siswa Disabilitas, Sekolah Inklusif, Guru Pendidikan Khusus.

How to Cite: Amalia, N., \& Kurniawati, F. (2021). Studi Literatur: Peran Guru Pendidikan Khusus di Sekolah Inklusi. Jurnal Kependidikan: Jurnal Hasil Penelitian dan Kajian Kepustakaan di Bidang Pendidikan, Pengajaran dan Pembelajaran, 7(2), 361-371. doi:https://doi.org/10.33394/jk.v7i2.3730

d.

https://doi.org/10.33394/jk.v7i2.3730

This is an open-access article under the CC-BY-SA License.

\section{Pendahuluan}

Undang-Undang Kementerian Pendidikan dan Kebudayaan No 8 Pasal 1 Tahun 2016 menjelaskan bahwa penyandang disabilitas adalah setiap orang yang mengalami keterbatasan fisik, intelektual, mental, dan/atau sensorik dalam jangka waktu lama yang dalam berinteraksi dengan lingkungan dapat mengalami hambatan dan kesulitan untuk berpartisipasi secara penuh dan efektif dengan warga negara lainnya. Menurut Heward (2003) anak disabilitas merupakan anak dengan karakteristik khusus yang menunjukkan ketidakmampuan mental, 
emosi, atau fisik. Mangunsong (2009) berpendapat bahwa anak disabilitas adalah anak yang menyimpang dari rata-rata anak normal dalam ciri-ciri mental, kemampuan sensorik, fisik, neuromaskular, sosial, dan emosi. Berdasarkan beberapa definisi ahli disimpulkan bahwa anak disabilitas adalah anak yang memiliki kelainan secara fisik, emosi, dan mental serta membutuhkan bantuan orang lain untuk memenuhi kebutuhan hidupnya.

Penyandang disabilitas dalam memenuhi pendidikannya telah disediakan sistem layanan pendidikan secara khusus dan inklusif yang diatur dalam UU no 8 tahun 2016 pasal 10. Salah satu sistem pendidikan khusus yang dimaksud adalah pendidikan luar biasa, namun sekolah luar biasa memiliki beberapa kelemahan seperti terbatasnya sosialisasi anak disabilitas, dan mahalnya biaya pendidikan (Santoso, 2012). Oleh karena itu, Pemerintah menyediakan pendidikan inklusif sebagai solusi untuk mengatasi kekurangan SLB dimana siswa penyandang disabilitas dapat belajar bersama siswa reguler tanpa mengeluarkan biaya mahal (Jauhari, 2017).

Sistem pendidikan inklusif diatur dalam Peraturan Pendidikan yang dikeluarkan oleh Menteri Pendidikan Nomor 70 Tahun 2009. Pada pelaksanaannya, keberhasilan pendidikan inklusi terhadap pembelajaran anak disabilitas dipengaruhi oleh beberapa faktor yaitu pandangan, kebijakan sekolah, kerjasama dan koordinasi antara guru kelas dengan guru pendidikan khusus serta kemampuan mengajar guru (Chopra, 2008). Berdasarkan beberapa faktor di atas diketahui bahwa peran guru pendidikan khusus menjadi salah satu faktor yang mempengaruhi keberhasilan pembelajaran di sekolah inklusif (Giangreco, 2013).

Keberadaan guru pendidikan khusus penting karena guru reguler merasakan banyak beban ketika menghadapi peserta didik disabilitas atau kesulitan belajar dimana mereka membutuhkan waktu dan perhatian yang lebih banyak daripada teman-teman yang lain dan tidak menunjukkan hasil yang sesuai harapan (Lopes et al., 2004). Oleh karena itu, guru reguler membutuhkan bantuan guru pendidikan khusus dalam menangani pembelajaran anak disabilitas di kelas. Guru pendidikan khusus merupakan guru yang mempunyai latar belakang pendidikan khusus atau yang pernah mendapat pelatihan tentang pendidikan khusus yang ditugaskan di sekolah inklusif (Depdiknas. 2007).

Blatchford et al (2009) menyatakan bahwa terdapat dua peran yang dijalankan oleh guru pendidikan khusus yaitu peran pedagogik dan non pedagogik. Peran pedagogik yang dilakukan yaitu bertanggung jawab untuk pengajaran, perencanaan pembelajaran, memberikan instruksi, menyusun kurikulum alternatif, menyiapkan program intervensi, dan membuat atau memodifikasi konten dan materi pelajaran dalam mengadaptasi tugas-tugas sehingga dapat diakses atau dicapai murid disabilitas (Webster \& Blatchford, 2011). Peran non pedagogik yaitu administrasi, dukungan emosional, mendorong kemandirian dan kepercayaan diri peserta didik (Webster \& Blatchford, 2011).

Peran guru pendidikan khusus dikatakan efektif dilihat dari pencapaian dan pembelajaran siswa (Creemers, 1994). Sayangnya, tidak semua peran guru pendidikan khusus dapat terlaksana sebagaimana mestinya (Mulyani, 2017). Terdapat beberapa kasus yang menunjukkan adanya ketidaksesuaian peran yang dijalankan guru pendidikan khusus seperti mengajar di depan kelas, menyiapkan bahan dan media pembelajaran, menyiapkan kelas, mengatur jadwal siswa (Abbott et al., 2011).

Ketidaksesuaian peran guru pendidikan khusus ini terjadi karena kurangnya pemahaman dan pengetahuan guru kelas mengenai peran guru pendidikan khusus dalam pembelajaran inklusif (Webster \& Blatchford, 2013). Guru pendidikan khusus merupakan guru yang dipekerjakan untuk membantu guru kelas dalam memberikan pengajaran terhadap anak disabilitas yang membutuhkan bantuan bukan berarti menggantikan peran guru kelas (Radford et al., 2014). Hasil penelitian berbeda menunjukkan bahwa beberapa sekolah inklusi 
di Cirebon dan Yogyakarta berhasil membuat guru pendidikan khusus menjalankan perannya yaitu mendampingi dan mendorong siswa disabilitas untuk terlibat dalam menyelesaikan tugas dengan cara meningkatkan partisipasi dalam kegiatan belajar (Webster et al., 2010), mendampingi siswa di dalam dan luar kelas (Triyanto \& Permatasari, 2017) dan membuat program pembelajaran individual atau PPI (Parwoto, 2007).

Keberagaman peran yang dijalankan guru pendidikan khusus dapat mempengaruhi hasil pembelajaran pada siswa disabilitas (Blatchford et al., 2009). Pengaruh tersebut dapat berupa pengaruh positif ataupun negatif. Pengaruh positif yang terjadi adanya peningkatan hasil pembelajaran siswa disabilitas (Giangreco, Broer, \& Edelman, 2001) sedangkan pengaruh negatif yaitu kesalahan pengambilan keputusan, meningkatkan ketergantungan dan menyebabkan hubungan sosial yang kurang baik dengan teman sebaya (Hall \& McGregor, 2000).

Dari penjabaran tersebut, diperoleh bahwa peran guru pendidikan khusus terhadap anak disabilitas masih beragam. Oleh karena itu, dibutuhkan studi mendalam tentang peran guru pendidikan khusus di sekolah inklusif. Berdasarkan permasalahan diatas, maka tujuan dari studi ini adalah menyediakan tinjauan literatur mengenai peran yang dijalankan guru pendidikan khusus di sekolah inklusi untuk membantu pembelajaran siswa disabilitas.

Kajian literatur ini menggunakan teori peran dari Webster dan Blatchford (2011) yang menjelaskan bahwa peran guru pendidikan khusus yaitu peran pedagogik dan non pedagogik. Peran pedagogik yang dimaskud yaitu bertanggung jawab untuk pengajaran, perencanaan pembelajaran, memberikan instruksi, menyusun kurikulum alternatif, menyiapkan program intervensi, membuat atau memodifikasi konten dan materi pelajaran dalam mengadaptasi tugas-tugas untuk murid sehingga dapat diakses atau dicapai murid dan memantau serta mengelola perilaku. Peran non pedagogik yaitu melakukan administrasi, dukungan emosional, mendorong kemandirian, dan membangun kepercayaan diri.

\section{Metode Penelitian}

Metode penelitian yang digunakan dalam penelitian ini adalah studi literature review. Pada kajian literatur ini sumber data berasal dari artikel yang dipublikasikan dalam waktu 10 tahun terakhir terhitung dari bulan Januari 2010 hingga Desember 2019. Kriteria inklusi yang digunakan dalam penelitian ini adalah guru pendidikan khusus dan siswa disabilitas yang bersekolah di sekolah inklusif mulai dari tingkat pendidikan dasar hingga sekolah menengah atas. Kriteria eksklusi subjek pada penelitian ini adalah guru pendidikan khusus dan siswa yang bukan berada di jenjang SD hingga SMA dan topik penelitian yang tidak terkait dengan peran guru seperti faktor psikologis, persepsi, dan lainnya. Pencarian dalam penelitian ini menggunakan 1 jenis database yaitu Taylor \& Francis Online. Kata kunci pencarian yang digunakan adalah "teacher assistant", "inclusive school", "special needs", dan "disability" untuk memperoleh artikel yang relevan. Setelah melakukan penyaringan artikel diperoleh 10 artikel ilmiah yang membahas mengenai peran guru pendidikan khusus sesuai dengan kriteria yang telah ditetapkan. Artikel yang termasuk dalam kriteria akan digunakan untuk dianalisa. Analisa data penting karena berhubungan dengan penarikan kesimpulan. Teknik analisis data yang digunakan dalam penelitian ini adalah tematik analisis. Analisa tematik adalah metode yang digunakan untuk mengidentifikasi data secara detail mengenai suatu tema penelitian.

\section{Hasil Penelitian dan Pembahasan}

Berdasarkan hasil penyaringan artikel ditemukan 10 artikel terkait peran guru pendidikan khusus. Pada 10 artikel tersebut diperoleh 3 artikel studi kualitatif, 2 artikel studi kuantitatif, dan 5 artikel gabungan studi kualitatif dan kuantitatif. Berdasarkan asal negara 
dilakukannya penelitian diperoleh bahwa 4 artikel dari Inggris, 2 artikel Australia, 1 artikel Swedia, 1 artikel Finlandia, 1 artikel Spanyol, dan 1 artikel Republik Ceko. Artikel yang diperoleh merupakan artikel yang berkaitan dengan peran guru pendidikan khusus di sekolah inklusi. Di bawah ini merupakan tabel 1 yang berisi ringkasan 10 studi terkait peran guru.

Tabel 1. Ringkasan Studi Penelitian

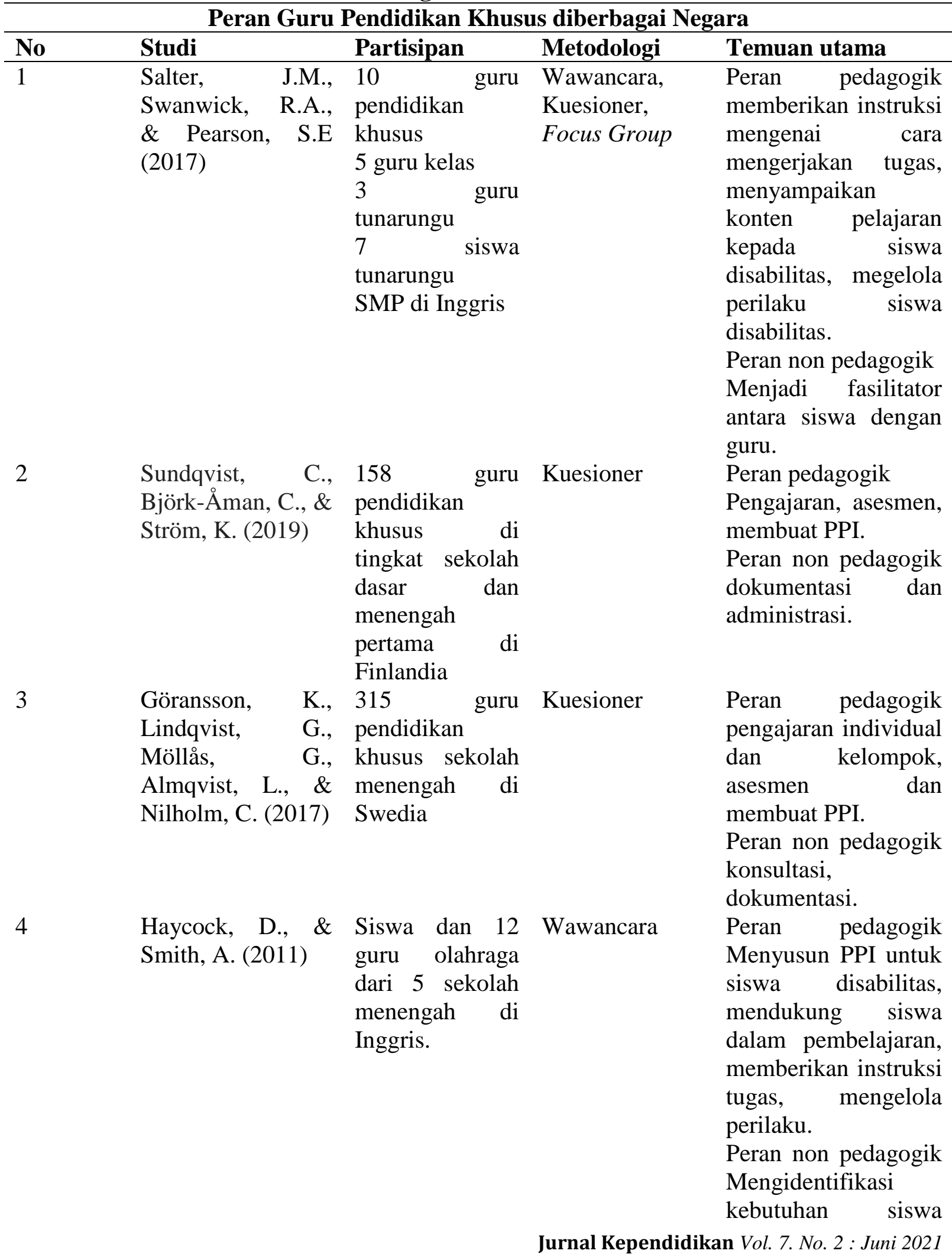


Jardí,

A., 101

Puigdellívol, I., \& pendidikan

Petreñas, C. (2018) khusus di sekolah umum

Catalan,

Spanyol

6

Clarke, E., \& 2 kelompok Visser, J. (2019) sampel.

Kelompok sampel pertama berjumlah 13 guru pendidikan khusus dan kelompok sampel kedua berjumlah 17 guru pendidikan khusus pada sekolah dasar di Inggris

Williams, K.E., \& $8 \quad$ kelompok O'Connor, $\mathrm{M}$ anak-anak yang (2012) terdiri dari 6 siswa, $\quad 4$ kelompok orang tua dari 8 sekolah dasar Inggris

145 partisipan, terdiri dari 44 GPK, 39 guru kelas, 14 guru honorer, 36 pemimpin disabilitas.

Peran pedagogik

mendukung siswa berpartisipasi aktif dalam pembelajaran, memberikan

penjelasan dan instruksi ulang kepada siswa, asesmen siswa, mengawasi dan mengatasi masalah perilaku siswa.

Peran non pedagogik menjalin komunikasi dengan keluraga siswa disabilitas. Peran pedagogik Melakukan kolaborasi dengan guru dalam mengelola kelas. Peran non pedagogik Menjalin komunikasi dengan guru dan murid.

$\begin{array}{ll}\text { Wawancara } & \text { Peran pedagogik } \\ & \text { Membantu guru } \\ & \text { untuk memastikan } \\ & \text { anak terlibat dalam } \\ & \text { menyelesaikan tugas, } \\ & \text { mengelola dan } \\ & \text { mengatur anak } \\ & \text { disabilitas } \\ & \text { Peran non pedagogik } \\ & \text { menjalin komunikasi } \\ & \text { dengan siswa. } \\ \text { Kuesioner, } & \text { Peran pedagogik } \\ \text { Wawancara } & \text { Membantu } \\ & \text { pembelajaran siswa } \\ \text { disabilitas, } & \text { memberikan instruksi } \\ & \text { pembelajaran kepada }\end{array}$


sekolah dan 12

orang tua.

Partisipan

tersebut diambil

dari 61 sekolah

di 61 sekolah di

Australia.

\section{3 partisipan}

8 guru

pendidikan

khusus

48 guru

11 kepala

sekolah

Supervisi 4

2 staff sekolah

4 sekolah sd di

Australia anak disabilitas.

Peran non pedagogik

Melakukan interaksi

dengan anak

disabilitas, menjalin

komunikasi dengan

orang tua siswa

disabilitas.

Kuesioner, Peran pedagogik

Wawancara, Memberikan

Observasi

dukungan pengajaran

kepada guru dan

siswa disabilitas,

Membantu

memindahkan meja

dan kursi, mengelola

perilaku siswa.

Peran non pedagogik membangun

komunikasi dengan

keluarga anak

disabilitas.

Peran pedagogik

Membantu

pengorganisasian

siswa disabilitas,

Mendukung

pembelajaran siswa

di kelas,

Mempersiapkan alat peraga, mengecek PR, membuat materi pendidikan.

Peran non pedagogik

Membantu menjalin

komunikasi antara guru dengan orang tua siswa disabilitas

Membantu perawatan diri dan mobilitas siswa disabilitas.

Berdasarkan temuan penelitian ini, terdapat peran yang dilakukan guru pendidikan khusus berupa peran pedagogic dan non pedagogic. Disamping itu, ditemukan tanggung jawab pekerjaan yang tidak sesuai dengan peran pedagogik guru pendidikan khusus. Peran pedagogic guru pendidikan khusus meliputi pengajaran, instruksi tugas, membuat PPI, melakukan asesmen dan mengelola perilaku siswa dan peran non pedagogic yaitu menjadi fasilitator, memberikan dukungan emosional, dan konsultasi. Peran non pedagogik tersebut bertujuan membantu membangkitkan kemandirian siswa dalam memenuhi kebutuhan 
hidupnya. Dengan adanya interaksi antara guru, guru pendidikan khusus dan orang tua diharapkan mampu berkontribusi membantu meningkatkan perkembangan pada anak disabilitas. Sebaliknya, ditemukan peran pedagogic yang bukan menjadi tanggung jawab tugas guru pendidikan khusus melainkan guru kelas yaitu mempersiapkan alat peraga, membuat materi pendidikan untuk siswa (Nemec et al.,2015). Hal ini sesuai dengan studi Rusman (2016) bahwa mempersiapkan kelas dan membuat materi pembelajaran merupakan tanggung jawab guru kelas. Temuan ini membuktikan adanya pergeseran peran yang awalnya merupakan peran guru kelas berubah menjadi peran guru pendidikan khusus (Mulyani, 2016).

Hasil temuan lainnya terkait pentingnya guru pendidikan khusus memiliki kompetensi sesuai dengan latar belakang pendidikan dan perlunya pembelajaran kolaborasi antara guru kelas dengan guru pendidikan khusus dalam pembelajaran. Guru pendidikan khusus merupakan seseorang yang memiliki keterampilan, keahlian, dan pengetahuan untuk menangani kebutuhan anak disabilitas terutama dalam memberikan pengajaran untuk siswa disabilitas. Temuan tersebut sejalan dengan studi Carter et al (2019) dan Goransson (2017) bahwa guru pendidikan khusus merupakan orang yang memiliki gelar kekhususan dibidangnya dan sudah terlatih atau berpengalaman dalam menangani anak disabilitas. Guru pendidikan khusus yang kompeten dapat membantu terlaksananya keberhasilan pembelajaran siswa disabilitas (Giangreco, 2013). Hal ini sesuai temuan Webster dan Blatchford (2013) bahwa keberhasilan pendidikan khusus tergantung pada kualitas guru pendidikan khusus. Oleh karena itu, guru pendidikan khusus merupakan orang yang memiliki kualifikasi atau telah diberikan pelatihan mengenai cara penanganan siswa disabilitas.

Hal penting lainnya yaitu terkait pelaksanaan pembelajaran di kelas, Guru dan guru pendidikan khusus membutuhkan kolaborasi dalam menjalankan pengajaran di kelas. Hal ini diperuntukkan untuk membangun pembelajaran yang efektif bagi siswa. Pembelajaran kolaboratif yang terjadi ditunjukkan dengan adanya diskusi dan berbagi tanggung jawab antara guru dan guru pendidikan khusus (Pesonen et al. 2015; Takala and Head, 2017). Pembelajaran kolaborasi akan menghasilkan dampak positif pada hasil pembelajaran siswa (Panula, 2013). Hal ini sesuai dengan studi (Blatchford et al., 2009) bahwa kolaborasi yang terjadi antara guru dengan guru pendidikan khusus dapat menghasilkan dampak positif terhadap kemajuan siswa disabilitas. Pengaruh positif yang terjadi yaitu meningkatkan perhatian dan dukungan pembelajaran, meningkatkan efektivitas pengajaran, meningkatkan manajemen kelas, dan mempengaruhi hasil pembelajaran siswa (Blatchford, 2002). Oleh karena itu, pembelajaran kolaborasi penting dilakukan antara guru dan guru pendidikan khusus untuk meningkatkan kemajuan siswa disabilitas.

\section{Kesimpulan}

Kesimpulan yang diperoleh dari hasil studi literatur ini adalah peran yang dijalankan guru pendidikan khusus yaitu peran pedagogik dan non pedagogik pada siswa disabilitas di sekolah inklusi. Peran pedagogik meliputi pengajaran, memberikan instruksi tugas, membantu siswa fokus menyelesaikan tugas, membuat PPI, dan melakukan asesmen. Peran non pedagogik meliputi membantu manajemen diri dalam mengelola perilaku siswa disabilitas, dukungan emosional, konsultasi, dan menjalin komunikasi dengan guru, orang tua dan siswa. Selain itu, pentingnya guru pendidikan khusus memiliki kompeten di bidangnya serta diperlukannya kolaborasi antara guru dengan guru pendidikan khusus sehingga menghasilkan pembelajaran yang efektif untuk anak disabilitas. 


\section{Saran}

Berdasarkan hasil penelitian ini, maka saran yang disampaikan yaitu: (1) pihak sekolah, memberikan jobdesk yang jelas mengenai peran guru kelas dan guru pendidikan khusus untuk menghindari terjadinya overlap peran antar keduanya; (2) untuk guru, memiliki pendidikan yang sesuai dengan tanggung jawab perannya dimana guru pendidikan khusus harus memiliki background pendidikan berkaitan siswa disabilitas yaitu lulusan pendidikan luar biasa (PLB) sedangkan guru kelas berlatar belakang pendidikan dengan kebutuhan siswa; (3) Stakeholder, diharapkan lebih memperhatikan kesejahteraan guru pendidikan khusus dengan memberikan bantuan insentif dan fasilitas dalam proses pembelajaran di sekolah inklusi sehingga mereka dapat menjalankan perannya dengan baik; (4) untuk peneliti lainnya dapat mengembangkan penelitian dengan mengaitkannya pada konteks lain seperti hambatan dalam menjalankan peran guru pendidikan khusus di sekolah inklusi.

\section{Daftar Pustaka}

Abbott, L., McConkey, R., \& Dobbins, M. (2011). Key players in inclusion: Are we meeting the professional needs of learning support assistants for pupils with complex needs?. European Journal of Special Needs Education,26(2), 215-231. https://doi.org/10.1080/08856257.2011.563608

Blatchford, P., Bassett, P., Brown, P., Martin, C., Russell, A., \& Webster, R. (2009). Deployment and impact of support staff in schools: Characteristics, working conditions and job satisfaction of support staff in schools (Strand 1, Waves 1-3 in 2004, 2006 and 2008). DCSF. http://maximisingtas.co.uk/assets/content/disss1w123r.pdf

Blatchford, P., Martin, C., Moriarty, V., Bassett, P., \& Goldstein, H. (2002, May). Pupil adult ratio differences and educational progress over reception and key stage 1. DfES. Blatchford, P., Martin, C., Moriarty, V., Bassett, P. \& Goldstein, H. (2002). Pupiladult ratio differences and educational progress over Key Stage 1. Final Report to the DfES (London, DfES). https://dera.ioe.ac.uk/4603/1/RR335.pdf

Bourke, P., \& Carrington, S. (2007). Inclusive education reform: Implications for teacher aides. Australasian Journal of Special Education,31(1), 15-24. https://doi.org/10.1080/10300110601184701

Butt, R. (2016). Teacher assistant support and deployment in mainstream schools. International Journal of Inclusive Education, 20(9), 995-1007. https://doi.org/10.1080/13603116.2016.1145260

Cameron, D. L. (2014). An examination of teacher-student interactions in inclusive classrooms: Teacher interviews and classroom observations. Journal of Research in Special Educational Needs, 14(4), 264-273. https://doi.org/10.1111/1471-3802.12021

Carter, M., Stephenson, J., \& Webster, A. (2019). A survey of professional tasks and training needs of teaching assistants in New South Wales mainstream public schools. Journal of Intellectual \& Developmental Disability, 44(4), 447-456. https://doi.org/10.3109/13668250.2018.1462638

Chopra, R. (2008, September 3-6). Factors influencing elementary school teachers' attitude towards inclusive education. British Educational Research Association Annual 
Conference, Heriot-Watt University, Edinburgh, Scotland. http://www.leeds.ac.uk/educol/documents/174842.pdf

Clarke, E., \& Visser, J. (2016). Teaching assistants managing behavior who knows how they do it? A review of literature. Support for learning,31(4), 266-280. https://doi.org/10.1111/1467-9604.12137

Clarke, E., \& Visser, J. (2019). Is a good teaching assistant one who 'knows their place'?. Emotional and Behavioural Difficulties, 24(4), 308-322. https://doi.org/10.1080/13632752.2019.1625207

Creemers, B. P. M. (1994). The effective classroom. London: Cassell.

Giangreco, M. F. (2013). Teacher assistant supports in inclusive schools: Research, practices and alternatives. Australasian Journal of Special Education, 37(2), 93-106. https://doi.org/10.1017/jse.2013.1

Giangreco, M. F., \& Broer, S. M. (2005). Questionable utilization of paraprofessionals in inclusive schools: Are we addressing symptoms or causes?. Focus on autism and other developmental 10-26. https://doi.org/10.1177/10883576050200010201

Giangreco, M. F., Suter, J. C., \& Hurley, S. M. (2013). Revisiting personnel utilization in inclusion-oriented schools. The Journal of Special Education,47(2), 121-132. https://doi.org/10.1177/0022466911419015

Göransson, K., Lindqvist, G., Möllås, G., Almqvist, L., \& Nilholm, C. (2017). Ideas about occupational roles and inclusive practices among special needs educators and support teachers in Sweden. Educational review, 69(4), 490-505. https://doi.org/10.1080/00131911.2016.1237477

Hall, L. J., \& McGregor, J. A. (2000). A follow-up study of the peer relationships of children with disabilities in an inclusive school. The Journal of Special Education, 34(3), 114126. https://doi.org/10.1177/002246690003400301

Haycock, D., \& Smith, A. (2011). To assist or not to assist? A study of teachers' views of the roles of learning support assistants in the provision of inclusive physical education in England. International Journal of Inclusive Education, 15(8), 835-849. https://doi.org/10.1080/13603110903452325

Heward, W.L. (2003). Exceptional children: An introduction to special education. New Jersey: Merril, Prentice Hall.

Jardí, A., Puigdellívol, I., \& Petreñas, C. (2018). Teacher assistants' roles in Catalan classrooms: Promoting fair and inclusion-oriented support for all. International Journal of Inclusive 1-16. https://doi.org/10.1080/13603116.2018.1545876

Jauhari, Auhad. (2017). Pendidikan inklusi sebagai alternatif solusi mengatasi permasalahan sosial anak penyandang disabilitas. Jurnal IJTIMAIYA, 1(1), 23-38. https://doi.org/10.1234/ji.v1i1.3099

Lopes, J. A., Monteiro, I., Sil, V., Rutherford, R. B., \& Quinn, M. M. (2004). Teachers' perceptions about teaching problem students in regular classrooms. Education and treatment of children, 394-419. 
Mangunsong, F. (2009). Psikologi dan pendidikan anak berkebutuhan khusus. Depok: LPSP3 UI.

Mulyani, G., \& Marlina, M. (2017). Pelaksanaan tugas pokok guru pendidik khusus di sekolah penyelenggara pendidikan inklusif. Jurnal Penelitian Pendidikan Khusus, 5(2). https://doi.org/10.24036/jupe75930.64

O'Rourke, J., \& West, J. (2015). Education assistant support in inclusive Western Australian classrooms: Trialling a screening tool in an Australian context. International Journal of Disability, Development and Education, 62(5), 531-546. http://doi/full/10.1080/1034912X.2015.1052376

Němec, Z., Šimáčková-Laurenčíková, K., Hájková, V., \& Strnadová, I. (2015). 'When I need to do something else with the other children, then I can rely on her': teaching assistants working with socially disadvantaged students. European Journal of Special Needs Education, 30(4), 459-473. https://doi.org/10.1080/08856257.2015.1035904

Panula, A. M. (2013). Reading difficulties and part time special education-a follow up from preschool to the end of 9 th grade (.Unpublished dissertation)., University of Helsinki, Finland.

Pesonen, H., Itkonen, T., Jahnukainen, M., Kontu, E., Kokko, T., Ojala, T., \& Pirttimaa, R. (2015). The implementation of new special education legislation in Finland. Educational Policy, 29(1),

162-178. https://doi.org/10.1177/0895904814556754

Radford, J., Bosanquet, P., Webster, R., \& Blatchford, P. (2015). Scaffolding learning for independence: Clarifying teacher and teaching assistant roles for children with special educational needs. Learning and 1-10. https://doi.org/10.1016/j.learninstruc.2014.10.005

Radford, J., Bosanquet, P., Webster, R., Blatchford, P., \& Rubie-Davies, C. (2014). Fostering learner independence through heuristic scaffolding: A valuable role for teaching assistants. International Journal of Educational Research,63, 116-126. https://doi.org/10.1016/j.ijer.2013.02.010

Rose, R. (2000). Using classroom support in a primary school: A single school case study. British Journal of Special Education, 27(4), 191-96. https://doi.org/10.1111/1467-8527.00188

Salter, J. M., Swanwick, R. A., \& Pearson, S. E. (2017). Collaborative working practices in inclusive mainstream deaf education settings: teaching assistant perspectives. Deafness ～\& Education International, 19(1), 40-49. https://doi.org/10.1080/14643154.2017.1301693

Santoso, Hargio. (2012). Cara memahami \& mendidik anak berkebutuhan khusus. Yogyakarta: Gosyen Publishing.

Sundqvist, C., Björk-Åman, C., \& Ström, K. (2019). The three-tiered support system and the special education teachers' role in Swedish-speaking schools in Finland. European Journal of Special Needs Education, 34(5), 601-616. https://doi.org/10.1080/08856257.2019.1572094 
Takala, M., \& Head, G. (2017). Inclusion and practice: The perspective of two countries In M.T. Hughes \& E. Talbott (Eds.), The handbook of diversity in special education (pp.115-128). John Wiley Press. https://doi.org/10.1002/9781118768778

Vygotsky, L. S. (1971). The psychology of art. London: MIT press.

Webster, R., Blatchford, P., \& Russell, A. (2013). Challenging and changing how schools use teaching assistants: Findings from the effective deployment of teaching assistants project. School Leadership \& Management, 33(1), 78-96. https://doi.org/10.1080/13632434.2012.724672

Webster, R., Blatchford, P., Bassett, P., Brown, P., Martin, C., \& Russell, A. (2010). Double standards and first principles: Framing teaching assistant support for pupils with special educational needs. European journal of special needs education, 25(4), 319336. https://doi.org/10.1080/08856257.2010.513533

Webster, R., Blatchford, P., Bassett, P., Brown, P., Martin, C., \& Russell, A. (2011). The wider pedagogical role of teaching assistants. School Leadership and Management, 31(1), 3-20. https://doi.org/10.1080/13632434.2010.540562

Williams, K. E., \& O'Connor, M. (2012). The views of children and parents towards higher level teaching assistants who teach whole classes. Education 3-13, 40(2), 129-143. https://doi.org/10.1080/03004279.2010.489512 